\title{
Coral mortality, recovery and reef degradation at Mexico Rocks Patch Reef Complex, Northern Belize, Central America: 1995-1997
}

\author{
C.D. Burke ${ }^{1, *}$, T.M. McHenry ${ }^{2}$, W.D. Bischoff ${ }^{1}$, E.S. Huttig ${ }^{1}$, W. Yang ${ }^{1} \&$ L. Thorndyke ${ }^{1}$ \\ ${ }^{1}$ Department of Geology, Wichita State University, Wichita, KS 67260-0027, USA \\ ${ }^{2}$ Levine-Fricke, 316 N. Ridgewood, Wichita, KS 67208, USA \\ (*Author for correspondence: Tel.: +1-316-978-3140, Fax: +1-316-978-7229, E-mail: collette.burke@wichita.edu)
}

Key words: biotic phase shift

\begin{abstract}
The 1995 coral bleaching event in the western Caribbean was the first reported episode that significantly affected the Belize barrier and lagoonal patch reefs. Bleaching was attributed to a 2 mo period of warm water temperatures above $30{ }^{\circ} \mathrm{C}$. Near Ambergris Caye, barrier and patch reefs experienced up to $50 \%$ bleaching. At Mexico Rocks patch reef complex, the bleaching resulted in changes in reef health, community, and physical structure. Prior to the hyperthermal episode, patch reef surface area consisted of $47 \%$ healthy framework coral coverage, $12 \%$ secondarily colonized biotic coverage, $35 \%$ dead coral surfaces that were degraded by biological activity and physical erosion, and $6 \%$ cavities. six months after bleaching, most corals had regained their color, but, owing to coral mortality, areas of surface degradation had increased to an average $49 \%$ ( $p=0.029$ based on Kruskal-Wallis analyses). Eighteen months after bleaching, degraded surface areas expanded to $53 \%(p=0.0366)$. Although re-coloring indicates rapid recovery for surviving corals, the persistence in dead coral surfaces suggests that reef skeletal structure recovery lags behind that of individual corals. Initial results of framework measurements indicate that bleaching events may result in an 'imbalance' in the carbonate production rate of coral reefs and produce mass wasting of the skeletal structure. Remapping of reef skeletal structure should establish quantitative measures for the long-term effects of bleaching on patch reef frameworks.
\end{abstract}

\section{Introduction}

Coral bleaching as a result of higher than average water temperatures commonly has been associated with El Nino/Southern Oscillation events as reported in the Pacific in 1982-1983, 1987, and 1998 (Glynn, 1988a, 1993; Viets, 1998). Elevated sea surface temperatures in the western Atlantic from August through October 1995 also produced widespread bleaching of corals from the Belize barrier and lagoonal patch reefs (Holden, 1995; CARICOMP, 1997). This event marked the first documented coral bleaching in this area (Stout, 1995). The Mexico Rocks patch reef complex, located $0.3 \mathrm{~km}$ seaward of Ambergris Caye in northern Belize, was severely affected by this thermal episode, when surface water temperatures in the shallow back-reef area in northern Belize increased to $32-34{ }^{\circ} \mathrm{C}$ (Sprowls, 1995). Aerial and underwater surveys of the bleaching event indicated that as much as $50 \%$ of the corals were bleached both at Mexico Rocks and on the barrier reef (CARICOMP, 1997). This paper presents the effects of the 1995 bleaching episode at the Mexico Rocks patch reefs, summarizes short-term coral recovery since that time, and describes long-term effects on patch reef skeletal structure.

Bleaching occurs when stony corals lose or expel all or a portion of their endosymbionts (zooxanthellae). Several factors have been impli- 